\title{
Performance das firmas do agronegócio listadas no novo mercado da Bovespa: um estudo econométrico
}

\section{Performance of the agribusiness listed firms in new market Bovespa: a study econometric}

Rendimiento de las firmas del agronegocio listadas en el
nuevo mercado de Bovespa: un estudio econométrico

Michel Constantino ${ }^{1}$

Dany Rafael Fonseca Mendes ${ }^{2}$

Reginaldo Brito da Costa ${ }^{3}$

Alexander Bruno Pegorare ${ }^{4}$

${ }^{1}$ Doutor em Economia pela Universidade Católica de Brasília (UCB). Mestre em Desenvolvimento Local (UCDB). Professor nos Programas de Doutorado em Ciências Ambientais e Sustentabilidade Agropecuária e em

Desenvolvimento Local. Pesquisador Visitante do Instituto de Pesquisa Econômica e Aplicada- IPEA-Brasília/DF. Vice Coordenador do Programa de Mestrado e Doutorado em Desenvolvimento Local. E-mail: michel@ucdb.br

${ }^{2}$ Mestrado em Análise Econômica do Direito pela Universidade Católica de Brasília (2014) e bacharelado em Direito pela Universidade Federal de Ouro

Preto (2008). Pesquisador, consultor, advogado e orientador do Programa Agentes Locais de Inovação do Serviço Brasileiro de Apoio às Micro e Pequenas Empresas. E-mail: rafael.dany@gmail.com

${ }^{3}$ Doutorado em Ciências Florestais pela Universidade Federal do Paraná (1999). Mestrado em Ciências Florestais pela Escola Superior de Agricultura Luiz de Queiroz (1988). Professor titular da Universidade Católica Dom Bosco. Líder do Grupo de Pesquisa cadastrado no DGP/CNPq "Desenvolvimento, meio-ambien-

te e sustentabilidade". E-mail: reg.brito.costa@gmail.com

${ }^{4}$ Supervisor das Pesquisas Agropecuárias Nacionais oficiais realizadas pelo IBGE no estado de Mato Grosso do Sul. Mestrado em Agronomia (Produção Vegetal) pela Universidade Federal de Mato Grosso do Sul (2006). Tem experiência com as pesquisas Nacionais de Agricultura, Pecuária, Extrativismo

Vegetal, Silvicultura e Estoques. E-mail: alexander.pegorare@ibge.gov.br 
Resumo: Este estudo mediu o impacto da gestão na performance das empresas do setor de agronegócio listadas na Bovespa, por meio de modelagem econométrica com dados em painel. A metodologia partiu da análise de nove indicadores de desempenho e uma função de produção padrão. Foram utilizados dados trimestrais, de 2007:1 a 2011:4, das dez empresas listadas no Novo Mercado (NM) da Bovespa. A influência dos indicadores no produto da empresa revelou que as variáveis capital e trabalho continuam proporcionando maior impacto no resultado, e que variáveis interligadas ao mercado, como é o caso do lucro por ação, são quase insignificantes.

Palavras-chave: finanças corporativas; governança; dados em painel; econometria; modelagem.

\begin{abstract}
This study measured the impact of management on the performance of the agribusiness sector companies listed on the Bovespa, through econometric modeling with panel data. The method started from nine performance indicators analysis and a standard production function. Quarterly data were used, 2007: 1-2011: 4, the ten companies listed on the Novo Mercado / Bovespa. The influence of the indicators in the product the company revealed that the variable capital and labor continue providing greater impact on the outcome, and that variables connected to the market, such as earnings per share, are almost negligible.
\end{abstract}

Key words: corporate finance; governance; panel data; econometrics; modeling.

Resumen: Este estudio midió el impacto de la gestión en el desempeño de las empresas del sector de agronegocios listadas en la Bovespa, por medio de modelado econométrico con datos en panel. La metodología partió del análisis de nueve indicadores de desempeño y una función de producción estándar. Se utilizaron datos trimestrales, de 2007: 1 a 2011: 4, de las diez empresas listadas en el Nuevo Mercado (NM) de Bovespa. La influencia de los indicadores en el producto de la empresa reveló que las variables capital y trabajo continúan proporcionando mayor impacto en el resultado, y que variables interconectadas al mercado, como es el caso del lucro por acción, son casi insignificantes.

Palabras clave: finanzas corporativas; gobernanza; datos en panel; econometría; modelado. 


\section{INTRODUÇÃO}

As mutações ocorridas nas finanças corporativas citadas por Tirole (2006) aumentaram o campo de pesquisa em torno do crescimento da firma. Com o avanço na teoria inicial de Arrow e Debreu (1954) e a partir dos estudos de Modigliani e Miller (1958), a corrente de pesquisa passou de um equilíbrio geral dos mercados sem fricção para a análise das escolhas financeiras das empresas e suas estratégias de governança.

Com resultados notáveis, Modigliani e Miller (1958; 1963) mostraram que os resultados das firmas eram afetados pela escolha de sua estrutura financeira e, principalmente, pela maneira como as organizações eram geridas. Smith Jr. (1984) afirma que Modigliani e Miller (1958) mudaram definitivamente o papel da Economia nas discussões sobre a estrutura de capital, pois eles mostraram que as políticas de financiamento das empresas afetam o valor da firma.

A teoria do crescimento da firma destina-se, em uma de suas vertentes, a estudar diferenciais fundamentais que tratam do desempenho do seu foco principal, a firma. Dentre esses diferenciais ou recursos aplicados, o modo de coordenação, ou seja, a governança, é a fonte inicial deste estudo, que revela uma análise empírica de firmas de um setor específico que participa de um segmento incremental das empresas de capital aberto listadas na Bovespa.

Estudos de Penrose (1959), de Chandler Jr. (1992) e de outros autores contribuíram para o entendimento e aperfeiçoamento de análises da governança, pois estes são caracterizados como recursos gerenciais não comercializáveis, específicos da firma e endogenamente construídos. Bhagat e Bolton (2008) utilizaram uma análise econométrica para estudar a relação entre governança corporativa e desempenho, levando em conta a natureza endógena da relação entre governança e desempenho. 
O presente estudo teve por objetivo medir o impacto da gestão na performance das empresas do setor de agronegócio listadas no segmento NM da Bovespa, por meio de modelagem econométrica, utilizando dados em painel. A modelagem é quantitativa e derivada de uma função de produção distinta, sustentada por testes econométricos robustos e dados específicos de cada empresa. Reconhecendo que essas empresas do Novo Mercado já possuem certo grau de governança corporativa, a metodologia partiu da análise dos indicadores de desempenho mais utilizados na literatura, os quais, num total de nove, abrangem índices de lucratividade, liquidez, endividamento e rentabilidade, sendo verificado por meio das estimações a significância de cada indicador.

A partir de uma função de produção padrão, a modelagem utiliza os indicadores de desempenho como proxy para medir a governança ou os impactos da gestão no produto das firmas, ampliando a análise com testes de efeito fixo e efeito aleatório, por meio do teste de especificação de Hausman ${ }^{1}$. Foram utilizados dados trimestrais, de 2007:1 a 2011:4, das dez empresas listadas no Novo Mercado da Bovespa. As firmas representam o setor do agronegócio do NM e compõem 100\% da amostra. Serão investigadas BRFood, JBS, Minerva, M. Dias Branco, SLC, VAgro, Renar, Marfrig, Cosan e São Martinho. A análise recai sobre firmas do agronegócio em função da importância desse setor para a economia brasileira e pela especificidade mercadológica que depende de um grande número de variáveis para determinar seu sucesso empresarial. Este artigo foi divido em: introdução; revisão teórica; metodologia; estimação e resultados; e considerações finais, seguidas das referências.

${ }^{1}$ Efeito fixo versus efeitos variáveis - o teste de Hausman testa a hipótese nula de que o modelo deve ser especificado com um efeito aleatório contra efeito fixo (hipótese alternativa). 


\section{CRESCIMENTO DA FIRMA E GOVERNANÇA}

As pesquisas em torno da teoria do crescimento da firma ficaram evidentes e motivaram novos estudos a partir das contribuições de Penrose (1959), Chandler (1962, 1977 e 1990), além de Marris (1971) e Steindl (1952), que, com outros autores, desenvolveram abordagens correlatas para proporcionar análises entre empresas e o crescimento. Seguindo Penrose (1959), a firma é definida como uma coleção de recursos produtivos que podem ser utilizados de acordo os objetivos da direção da empresa. A análise microeconômica da firma realizada pela autora permite contribuições nos estímulos ou obstáculos internos, dando menor importância aos determinantes externos, o que corrobora o presente estudo por fundamentar-se em indicadores internos os quais avaliam a performance gerencial.

Integrar a teoria do crescimento da firma² e a governança é uma forma de expressar a contribuição de Penrose (1959) quando a autora esclarece que o motivo do crescimento das firmas pode ser explicado a partir da comprovação de que as decisões gerenciais de investimentos e endividamento das empresas são determinadas pelo seu resultado final: a lucratividade.

\subsection{Governança Corporativa e o Novo Mercado (NM)}

Com intuito de criar códigos de conduta mercadológicos a partir de princípios e melhores práticas de governança das firmas, a Organization for Economic Cooperation and Development (OECD, 2008) sugeriu aos países associados que desenvolvessem seus códigos, esperando que tal codificação proporcionasse um ambiente favorável ao alinhamento de interesses de acionistas e gestores.

\footnotetext{
${ }^{2}$ Chandler (1962) e Penrose (1959) mostram estratégias de crescimento, que não serão discutidos neste estudo.
} 
No Brasil, foram criados níveis diferenciados de governança corporativa, os quais foram elaborados pela Bolsa de Valores de São Paulo no final de 2000 e possuem critérios de adesão que buscam diminuir a assimetria informacional entre os investidores e as empresas participantes desses grupos e, assim, por meio de maior transparência das informações divulgadas, reduzir o custo de captação de recursos no mercado. A implantação de três segmentos especiais para listagem de ações, denominados Nível 1, Nível 2 e Novo Mercado, teve por objetivo proporcionar um ambiente de negociação que estimule o interesse dos investidores e a valorização das companhias. O que distingue cada um desses níveis é o grau de comprometimento com as regras específicas de governança.

O Novo Mercado ${ }^{3}$, conforme a Bovespa, trata-se do mais elevado padrão de Governança Corporativa. As companhias listadas no NM só podem emitir ações com direito de voto, as chamadas ações ordinárias (ON). Por se tratar de uma mudança relevante nas estruturas de capital das companhias, é comum que as empresas decididas a abrir o seu capital já tomem a decisão de integrar o segmento especial de listagem do Novo Mercado durante o processo de abertura do capital.

\subsection{Empresas do agronegócio brasileiro}

O setor agropecuário brasileiro representou aproximadamente 26\% do PIB nacional conforme estudos do Ministério da Agricultura Pecuária e Abastecimento (BRASIL, 2010), contribuindo de maneira exponencial para o crescimento da economia e equilíbrio da balança comercial. Nesse setor, estão listadas 29 firmas pela Bovespa, que são subdivididas conforme o Quadro 1, abaixo:

\footnotetext{
${ }^{3}$ Dados disponíveis em: <http://www.bmfbovespa.com.br/empresas/pages/empresas_novo-mercado.asp $>$.
} 


\begin{tabular}{|l|l|l|l|l|l|}
\hline \multirow{2}{*}{ Agricultura } & \multicolumn{5}{|c|}{ Alimentos Processados } \\
\cline { 2 - 6 } & $\begin{array}{c}\text { Açúcar e } \\
\text { Álcool }\end{array}$ & $\begin{array}{l}\text { Carnes e } \\
\text { Derivados }\end{array}$ & Laticínios & $\begin{array}{l}\text { Alimentos } \\
\text { Diversos }\end{array}$ & \multicolumn{1}{|c|}{ Café } \\
\hline Monsanto & Cosan & BRF Foods & Laep & H J Heinz & Cacique \\
\hline Rasip Agro & Cosan LTD & Excelsior & Monticiano & J. Macedo & $\begin{array}{l}\text { CAF } \\
\text { Brasília }\end{array}$ \\
\hline Renar & São Martinho & JBS & & Josapar & $\begin{array}{l}\text { Iguaçú } \\
\text { Café }\end{array}$ \\
\hline SLC Agrícola & Us. C. Pinto & MarFrig & & Kraft Foods & $\begin{array}{l}\text { Grãos e } \\
\text { Derivados }\end{array}$ \\
\hline & & Minerva & & $\begin{array}{l}\text { M. Dias } \\
\text { Branco }\end{array}$ & Clarion \\
\hline & & Minupar & & Marambaia & \\
\hline & & & & Oderich & \\
\hline
\end{tabular}

Quadro 1- Setores e empresas do agronegócio listadas na Bovespa Fonte: Bovespa (2012) ${ }^{4}$.

Nos dois sub setores, agropecuária e alimentos processados, as empresas são divididas em: agricultura, açúcar e álcool, carnes e derivados, laticínios, alimentos diversos, café e grãos e derivados. Essas empresas estão listadas na Bovespa e pertencem a seus respectivos segmentos de classificação.

As firmas que pertencem ao segmento do agronegócio e ainda estão listadas no Novo Mercado da Bovespa são as grandes companhias em seus setores e apresentam relevantes informações e mudanças no período pesquisado. O Quadro 2, abaixo, indica as empresas do NM pesquisadas.

\footnotetext{
${ }^{4}$ Dados disponíveis em: <http://www.bmfbovespa.com.br/Cias-Listadas/Empresas-
} Listadas/BuscaEmpresaListada.aspx?idioma=pt-wbr $\geq$. 


\begin{tabular}{|c|c|}
\hline Empresa do Agronegócio & Segmento Bovespa \\
\hline RENAR & Novo Mercado \\
\hline SLC AGRICOLA & Novo Mercado \\
\hline V-AGRO & Novo Mercado \\
\hline COSAN & Novo Mercado \\
\hline SAO MARTINHO & Novo Mercado \\
\hline BRF FOODS & Novo Mercado \\
\hline JBS & Novo Mercado \\
\hline MARFRIG & Novo Mercado \\
\hline MINERVA & Novo Mercado \\
\hline M.DIASBRANCO & Novo Mercado \\
\hline
\end{tabular}

Quadro 2 - Empresas do agronegócio listadas no

Novo Mercado da Bovespa

Fonte: Bovespa $(2012)^{5}$.

Segundo a Bovespa, essas empresas representam o maior grau de governança corporativa, pois, ao ingressar nesse segmento Novo Mercado, a transparência e modelo de governança dessas organizações empresariais devem estar de acordo com os critérios da instituição. Para avaliar o nível de governança e saber a sua influência sobre o desempenho da empresa, o presente estudo utilizou indicadores relacionados com os resultados de cada firma.

\subsection{Indicadores de finanças corporativas}

A firma tem múltiplos objetivos, como: aumentar o seu nível de competitividade, absorver novos segmentos de mercado, atender aos anseios da sociedade, buscar opções de financiamentos, ampliar prazos de pagamentos, aumentar a liquidez, melhorar a rentabilida-

\footnotetext{
${ }^{5}$ Observa-se que a empresa TEREOS também faz parte da lista do Novo Mercado da Bovespa, no entanto, ela se tornou participante a partir de 2010, o que limita sua análise, sendo retirada desta pesquisa.
} 
de etc. Porém o objetivo principal da firma é maximizar seu valor de mercado e, consequentemente, a riqueza dos acionistas.

Os principais indicadores de gestão que medem a performance da firma foram utilizados neste estudo para comparar o efeito da governança sobre os resultados. Os indicadores são divididos em variáveis de liquidez, variáveis de rentabilidade e variáveis de endividamento.

\subsubsection{Variáveis de liquidez}

Os índices de liquidez têm o objetivo de avaliar a capacidade de pagamento da empresa. De acordo com Assaf Neto (2006 ), os indicadores de liquidez evidenciam e mostram, de forma mensurável, a situação financeira de uma empresa frente a seus diversos compromissos financeiros. Na literatura, os índices mais utilizados são de liquidez corrente, seca e geral.

(i) Liquidez Corrente (LC) = Ativo Circulante / Passivo Circulante. Analisa a razão entre direitos e deveres de curto prazo da empresa. A análise desse índice mostra que, quanto maior o resultado dessa diferença, melhor será a capacidade de liquidez corrente $(>0)$.

(ii) Liquidez Seca (LS) = (Ativo Circulante - Estoque) / Passivo Circulante. Analisa a razão entre direitos e deveres de curto prazo da empresa, excluindo o estoque. A análise desse índice mostra que, quanto maior o resultado dessa diferença, melhor será a capacidade de liquidez seca $(>0)$.

(iii) Liquidez Geral (LG) = (Ativo Circulante + Realizável a Longo Prazo) / (Passivo Circulante + Passivo Não Circulante). Mostra a situação de longo prazo da empresa, pois calcula a razão entre os direitos e obrigações de longo prazo. A análise desse índice mostra que, quanto maior o resultado dessa diferença, melhor será a capacidade de liquidez geral $(>0)$. 


\subsubsection{Variáveis de rentabilidade}

Os indicadores de rentabilidade apresentam resultados expressivos da gestão dos recursos da firma. A rentabilidade do ativo e a rentabilidade do patrimônio refletem a proporção rentável a cada valor monetário investido no ativo e no patrimônio, respectivamente. (iv) Rentabilidade do Ativo (RA) = Lucro Líquido / Ativo Total Médio. É uma medida de eficiência gerencial, pois mostra o retorno obtido através dos recursos investidos no ativo. A rentabilidade deve ser positiva (>0) e, quanto maior, melhor.

(v) Rentabilidade do Patrimônio (RP) = Lucro Líquido / Patrimônio líquido. Essa rentabilidade complementa a rentabilidade do ativo, pois a análise fica mais completa ao medir a performance do lucro em relação ao capital próprio, que deve ser positiva (>0) e, quanto maior, melhor.

\subsubsection{Variáveis de endividamento}

Os índices de endividamento expressam o nível de participação de capital de terceiros na atividade da empresa, evidenciando a situação financeira da entidade e servindo de direcionador para as decisões financeiras, em termos de obtenção e aplicação de recursos. Além disso, mostram como se encontra o nível de endividamento da entidade (PEREZ JUNIOR; BEGALLI, 2009).

(vi) Endividamento Geral (ER) = Dívida Bruta / Patrimônio Líquido. A medida de endividamento geral extrai quanto a empresa tem captado de recursos de terceiros em relação ao capital próprio bruto. Sua variação é positiva quando o resultado for cada vez menor $(<0)$.

(vii) Endividamento líquido (EL) = Dívida Líquida / Patrimônio Líquido. A medida de endividamento geral extrai quanto a empresa tem 
captado de recursos de terceiros em relação ao capital próprio bruto. Sua variação é positiva quando o resultado for cada vez menor $(<0)$.

(viii) Dependência Financeiro (DF) = Dívida Bruta / Ativo Total. A medida apresenta a proporção dos recursos de terceiros em relação ao total de aplicações da empresa. Quanto maior o índice, maior será o risco para o credor, especialmente quando os ativos não forem tão líquidos; Resume-se em comportamento do ativo em relação à sua dívida bruta, e sua variação é positiva quando o resultado for cada vez menor $(<0)$.

\subsubsection{Variável de lucratividade}

Umas das medidas prioritárias em relação à análise da performance da firma é sua lucratividade. No caso das empresas de capital aberto essa lucratividade é calculada de várias formas, sendo que a mais utilizada pela literatura especializada é a medida do lucro por ação.

(ix) Lucro por Ação (LPA) = Lucro Líquido / Número Total de Ações. É o quociente da divisão do lucro líquido da companhia, em determinado período, pelo número de ações. Sua mensuração se dá por essa razão, e seu sinal esperado é positivo (>0), e, quanto maior for o resultado, melhor a performance medida pelo indicador.

No Quadro 3, abaixo, projetam-se e resumem-se todos os índices ou indicadores com sua fórmula de cálculo, descrição resumida e o sinal esperado para sua análise. 


\begin{tabular}{|c|c|c|c|}
\hline Indicadores & $\begin{array}{r}\text { Cálculo } \\
\end{array}$ & $\begin{array}{c}\text { Descrição } \\
\end{array}$ & Sinal Esperado \\
\hline Liquidez Corrente (LC) & Ativo Circulante/Passivo Circulante & Razão entre direitos e deveres de curto prazo & $\mathrm{dY} / \mathrm{dLC}>0$ \\
\hline Liquidez Seca (LS) & (Ativo Circulante - Estoque)/Passivo Circulante & $\begin{array}{l}\text { Razão entre direitos e deveres de curto prazo } \\
\text { excluindo do cálculo o estoque }\end{array}$ & $\mathrm{dY} / \mathrm{dLS}>0$ \\
\hline Liquidez Geral (LG) & $\begin{array}{l}\text { (Ativo Circulante + Realizável a Longo Prazo) / } \\
\text { (Passivo Circulante + Passivo Não Circulante) }\end{array}$ & $\begin{array}{l}\text { Situação de longo prazo da empresa, razão entre } \\
\text { direito e obrigações de LP }\end{array}$ & $\mathrm{dY} / \mathrm{dLG}>0$ \\
\hline Rentabilidade do Ativo (RA) & Lucro líquido/Ativo Total Médio & $\begin{array}{l}\text { Mede eficiência da gestão - retorno obtido em } \\
\text { relação ao total de recursos }\end{array}$ & $\Delta \%>0$ \\
\hline $\begin{array}{l}\text { Rentabilidade do Patrimônio } \\
\text { (RP) }\end{array}$ & Lucro líquido/Patrimônio Líquido & $\begin{array}{l}\text { Mede a performance do lucro em relação ao capital } \\
\text { próprio }\end{array}$ & $\Delta \%>0$ \\
\hline Endividamento Geral (EG) & Dívida Bruta/Patrimônio Líquido & $\begin{array}{l}\text { Quanto a empresa tem captado de terceiros em } \\
\text { relação ao capital próprio bruto }\end{array}$ & $\Delta \%<0$ \\
\hline Endividamento Líquido (EL) & Dívida Líquida/Patrimônio Líquido & $\begin{array}{l}\text { Quanto a empresa tem captado de terceiros em } \\
\text { relação ao capital próprio líquido }\end{array}$ & $\Delta \%<0$ \\
\hline Dependência Financeira (DF) & Dívida Bruta/Ativo Total & $\begin{array}{l}\text { Comprometimento do ativo em relação à sua divida } \\
\text { bruta }\end{array}$ & $\Delta \%<0$ \\
\hline Lucro por Ação (LPA) & Lucro Líquido/Número Total de Ações & $\begin{array}{l}\text { Representa a razão entre o lucro líquido e o número } \\
\text { total de ações }\end{array}$ & $\Delta \%>0$ \\
\hline
\end{tabular}

Quadro 3 - Indicadores, fórmulas de cálculo, descrição e sinal esperado

\section{METODOLOGIA}

O campo empírico de estudo inicia-se com um cenário de 29 empresas no segmento de consumo não cíclico da área do agronegócio. Dentre essa população, foram escolhidas para análise as empresas citadas como participantes do segmento Novo Mercado (NM), que se destacam pelo nível de governança avançada. No segmento NM, existem 11 empresas do agronegócio listadas, sendo que a empresa Tereos foi integrada há pouco tempo, o que não a qualifica para a presente análise, sendo então denominada uma amostra de dez empresas, que identifica $100 \%$ da amostra salvo as proporções utilizadas.

A partir da seleção inicial da amostra, foi definido o período de análise, sendo que os dados mercadológicos são limitados, pois há restrição quanto ao tempo que cada empresa faz parte da Bovespa. Assim foi escolhido um período que contemplasse todas as empresas com mais informações e detalhes possíveis, levando a delimitar o período de 2007:1 a 2011:4, com dados trimestrais das dez empresas, resultando 200 observações para análise e estimativa. 


\subsection{Variáveis utilizadas e tratamento dos dados}

As variáveis utilizadas partiram do objetivo, que foi de analisar o impacto da gestão na performance da firma.

Para estimação do modelo, foram escolhidas variáveis que são utilizadas na literatura específica e permitem contribuir para o desenvolvimento e inovação de novas modelagens que caracterizam fontes de mensuração e discussão sobre o crescimento da firma. No intuito de visualizar as escolhas e o tratamento, o Quadro 4, abaixo, demonstra o constructo analítico utilizado.

\begin{tabular}{|c|l|l|l|}
\hline Variável & \multicolumn{1}{|c|}{ Descrição } & \multicolumn{1}{c|}{ Dado Utilizado } & \multicolumn{1}{c|}{ Tratamento } \\
\hline Y & \multicolumn{1}{|c|}{ Produto } & Conta de Imobilizado & $\begin{array}{l}\text { - Utilização da capacidade instalada na indústria - } \\
\text { Fonte: Fundação Getulio Vargas, Conjuntura } \\
\text { Econômica (FGV/Conj. Econ.) Unidade: (\%) } \\
\text { - Dado deflacionado pelo IGP-DI } \\
\text { Fonte: IPEADATA }\end{array}$ \\
\hline K & Capital & & Dado deflacionado pelo IGP-DI Fonte: IPEADATA \\
\hline L & Trabalho & Receita & Dado deflacionado pelo IGP-DI Fonte: IPEADATA \\
\hline Est & Estoque & Custo dos Produtos Vendidos & Dado deflacionado pelo IGP-DI Fonte: IPEADATA \\
\hline LPA & Lucro por Ação & Conta de Estoque & Dado Bruto \\
\hline LG & Liquidez Geral & Lucro por Ação & Dado Bruto \\
\hline LC & Liquidez Corrente & Liquidez Geral & Dado Bruto \\
\hline LS & Liquidez Seca & Liquidez Corrente & Dado Bruto \\
\hline DF & Dependência Financeira & Liquidez Seca & Dado Bruto \\
\hline EG & Endividamento Geral & Dependência Financeira & Dado Bruto \\
\hline EL & Endividamento Líquido & Endividamento Geral & Dado Bruto \\
\hline RA & Rentabilidade do Ativo & Endividamento Líquido & Dado Bruto \\
\hline RP & Rentabilidade do Patrimônio & Rentabilidade do Ativo & Dado Batrimônio \\
\hline
\end{tabular}

Quadro 4 - Variáveis, descrição e tratamento dos dados

Para o tratamento, os dados selecionados foram deflacionados pelo Índice Geral de Preços-Disponibilidade Interna (IGP-DI), e esse índice de inflação foi coletado do Instituto de Pesquisa Econômica Aplicada (IPEA). No caso da variável dependente Produto, foi utilizada a capacidade instalada da indústria para saber a participação correta na abordagem da conta do imobilizado. 


\subsection{Modelo e método}

A função de produção utilizada foi a clássica Cobb Douglas.

$$
Y=F(K, L)
$$

Para entender os efeitos e impactos da gestão, ou seja, do conjunto de indicadores na performance da firma, esse modelo foi incrementado.

$$
Y=(K, L, \text { Gov) }
$$

A variável independente Gov = Governança, que representa o conjunto de indicadores projetados para descobrir o impacto sobre o produto $(Y)$, é composta por:

$$
G o v=L P A+L G+L C+L S+D F+E G+E L+R A+R P
$$

Para complemento da análise, foram criados Dummys para cada empresa pesquisada e uma Dummy subprime para verificar o impacto da crise internacional de 2008 no modelo. A caracterização das Dummys ficou assim:

dBRF $d$ Cos dJBS dMdias dMarf dMin dRenar dSLC d Vagro dSaom e dSubP

Os métodos utilizados para estimação foram MQO (Mínimos Quadrados Ordinários) em todos os Modelos, de 1 a 4, sendo que, em cada modelo, foi analisado o efeito fixo e aleatório das respectivas variáveis. Para avaliar a consistência dos estimadores comparados e a adequação do modelo proposto, foi utilizado o teste de especificação de Hausman.

\section{ESTIMAÇÕES E RESULTADOS}

Para mensurar os impactos dos indicadores de gestão ao longo dos trimestres de 2007:1 a 2011:4 das empresas do setor de agronegócio listadas no segmento Novo Mercado da Bovespa, foi realizada a estimação de dados em painel com efeitos fixos e aleatórios. Destaque- 
se que as variáveis utilizadas nos modelos apresentados nas próximas subseções mostraram que os efeitos fixos e aleatórios são iguais, sendo então variáveis aleatórias, como mostra o Quadro 5, abaixo:

\begin{tabular}{|l|c|c|c|}
\hline Variável dependente ( Y ) & \multicolumn{3}{|c|}{ Efeitos } \\
\hline Variáveis & Fixo & Aleatório & Var(Diff.) \\
\hline Capital & 0.570868 & 0.570868 & 0.000000 \\
\hline Trabalho & 0.199608 & 0.199608 & 0.000000 \\
\hline Lucratividade & -0.005512 & -0.005512 & 0.000000 \\
\hline \multirow{2}{*}{ Liquidez } & 0.206822 & 0.206822 & 0.000000 \\
\hline \multirow{2}{*}{ Rentabilidade } & -0.037395 & -0.037395 & 0.000000 \\
\hline \multirow{3}{*}{ Endividamento } & 0.071357 & 0.071357 & 0.000000 \\
& -0.033843 & -0.033843 & 0.000000 \\
\hline & 0.006213 & 0.006213 & 0.000000 \\
\hline & -0.004971 & -0.004971 & 0.000000 \\
\cline { 2 - 4 } & 0.004630 & 0.004630 & 0.000000 \\
\hline
\end{tabular}

Quadro 5 - Testes de Especificação de Hausman

\subsection{Função de produção padrão}

O modelo 1 mostra que a equação do crescimento do produto (Y) depende positivamente das taxas de crescimento dos principais fatores de produção, como capital (K) e trabalho (L). Os coeficientes estimados de $(\Delta L / L)$ e $(\Delta K / K)$ apresentam valores equivalentes a 0.199608 e 0.570868, respectivamente, conforme Tabela 1 . Tais coeficientes são estatisticamente diferentes de zero, com probabilidades iguais a $0 \%$, para o trabalho e para o capital. A estimação com efeito fixo e/ou efeito aleatório não demonstrou diferença. 
Tabela 1 - Efeito dos principais fatores de produção

\begin{tabular}{|c|c|c|}
\hline \multicolumn{3}{|c|}{ Variável dependente: Y (produto) } \\
\hline \multicolumn{3}{|c|}{ Modelo 1 } \\
\hline Variáveis & Efeito Fixo & Efeito Aleatório \\
\hline \multirow{3}{*}{ C } & 0.893519 & 0.893519 \\
\cline { 2 - 3 } & $(0.139609)$ & $(0.139609)$ \\
\hline \multirow{3}{*}{ LogK } & {$[0.0000]$} & {$[0.0000]$} \\
\hline \multirow{3}{*}{ LogL } & 0.570868 & 0.570868 \\
\cline { 2 - 3 } & $(0.013850)$ & $(0.013850)$ \\
& {$[0.0000]$} & {$[0.0000]$} \\
\hline \multirow{3}{*}{} & 0.199608 & 0.199608 \\
& $(0.014198)$ & $(0.014198)$ \\
\hline & {$[0.0000]$} & {$[0.0000]$} \\
\hline
\end{tabular}

Nota: ( . ) = desvio-padrão; [ . ] = p-valor ou valor da probabilidade

Como o objetivo do trabalho foi de medir o impacto da gestão na performance das empresas, a partir do modelo básico (modelo 1 ), todos os indicadores de gestão foram acrescentados individualmente. Para uma análise geral dos modelos propostos de 1 a 4, demonstra-se a Tabela 2, abaixo, que indica a gradativa inserção das variáveis. 
Performance das firmas do agronegócio listadas no novo mercado da Bovespa: um estudo econométrico

Tabela 2 - Efeito dos indicadores de gestão na taxa de crescimento do produto

\begin{tabular}{|c|c|c|c|c|}
\hline \multicolumn{5}{|c|}{ Variável dependente: Y (produto) } \\
\hline Variáveis & Modelo 1 & Modelo 2 & Modelo 3 & Modelo 4 \\
\hline \multirow{3}{*}{ Taxa de Crescimento do capital (k) } & 0.570868 & 0.566688 & 0.452374 & 0.917859 \\
\hline & $(0.013850)$ & $(0.013238)$ & $(0.036926)$ & $(0.049884)$ \\
\hline & {$[0.0000]$} & {$[0.0000]$} & {$[0.0000]$} & {$[0.0000]$} \\
\hline \multirow{3}{*}{ Taxa de Crescimento do trabalho(L) } & 0.199608 & 0.194768 & 0.544413 & 0.029622 \\
\hline & $(0.014198)$ & $(0.013758)$ & $(0.028959)$ & $(0.033013)$ \\
\hline & {$[0.0000]$} & {$[0.0000]$} & {$[0.0000]$} & {$[0.0000]$} \\
\hline \multirow{3}{*}{ Indicador de Liquidez } & \multirow{3}{*}{$x x x x x x$} & 2.518 .591 & 0.301331 & 2.368 .176 \\
\hline & & $(5688062)$ & $(0.038308)$ & $(0.249703)$ \\
\hline & & {$[0.0000]$} & {$[0.0000]$} & {$[0.0000]$} \\
\hline \multirow{3}{*}{ Indicador de Rentabilidade } & \multirow{3}{*}{$\operatorname{xxxxxx}$} & \multirow{3}{*}{$\operatorname{xxxxxx}$} & 1.165 .858 & 0.215233 \\
\hline & & & $(0.133942)$ & $(0.044114)$ \\
\hline & & & {$[0.0000]$} & {$[0.0000]$} \\
\hline \multirow{3}{*}{ Indicador de Endividamento } & \multirow{3}{*}{$\operatorname{xxxxxx}$} & \multirow{3}{*}{$\operatorname{xxxxxx}$} & -0.000338 & -0.000577 \\
\hline & & & $(3.02 \mathrm{E}-05)$ & $(2.88 E-05)$ \\
\hline & & & {$[0.0000]$} & {$[0.0000]$} \\
\hline \multirow{3}{*}{ Indica dor de Lucrativida de } & \multirow{3}{*}{$x x x x x x$} & \multirow{3}{*}{$x x x x x x$} & \multirow{3}{*}{$x x x x x x$} & 0.440087 \\
\hline & & & & $(0.043479)$ \\
\hline & & & & {$[0.0000]$} \\
\hline
\end{tabular}

Nota: ( . ) = desvio-padrão; [ . ] = p-valor ou valor da probabilidade

Construídos e estimados quatro modelos na Tabela 2, a partir da função de produção standard, incrementando com o efeito do indicador de liquidez sobre o produto no modelo 2. Um novo modelo é estimado levando em consideração a taxa de crescimento do Capital, do Trabalho, o indicador de Liquidez e soma-se o efeito do indicador de Rentabilidade, estimando o modelo 3. Por fim, acrescenta-se o indicador de Lucratividade que resulta no modelo 4. Essa dinâmica de estimativas permite um procedimento vantajoso para mostrar se os coeficientes estimados são pouco sensíveis a mudanças devido à introdução de novas variáveis no modelo. Se esse for o caso, fica evidente que os coeficientes estimados são consistentes e não mudam com a 
introdução de novas variáveis. Pode-se observar que os coeficientes dos modelos 1 e 2, referentes à equação básica, são semelhantes por apresentarem valores estimados parecidos, com mesmo sinal e estatisticamente significantes.

Nos modelos 3 e 4, o Capital e Trabalho continuam significativos estatisticamente e o indicador de Endividamento mostra coeficiente negativo. É esperado que o resultado deste coeficiente de endividamento seja negativo, pois, além de um índice importante na área de finanças corporativas, ele indica o grau de alavancagem da firma. O indicador de Lucratividade apresentou pouca influência sobre o Produto, pois se credita o lucro por ação como output esperado após processos de mercado e gestão eficientes ou não.

Para compilar um estudo completo, foram realizadas estimações com todas as variáveis de maneira linear e não linear, além de incrementar uma análise de convergência e divergência entre a estimação realizada por meio do cruzamento das variáveis, e seus respectivos resultados foram confrontados com o sinal esperado de cada variável na Tabela 3. 
Tabela 3 - Indicadores de gestão, análise linear versus não linear e sinal esperado

\begin{tabular}{|c|c|c|c|}
\hline Variable & Coefficient & Sinal Esperado & Análise \\
\hline $\mathrm{C}$ & 3.006 .648 & & Convergente \\
\hline LOGK & 1.376 .760 & $(+)$ & Convergente \\
\hline LOGL & -0.311060 & & Divergente \\
\hline $\begin{array}{l}\mathrm{LG} \\
\mathrm{LG}^{*} \mathrm{LG}\end{array}$ & $\begin{array}{c}-5.457 .734 \\
2.717 .106\end{array}$ & $\mathrm{dY} / \mathrm{dLG}>0$ & $\begin{array}{c}\text { Divergente } \\
\text { Convergente }\end{array}$ \\
\hline $\begin{array}{l}\mathrm{EG} \\
\mathrm{EG} * \mathrm{EG}\end{array}$ & $\begin{array}{c}0.010800 \\
-0.000121\end{array}$ & $\Delta \%<0$ & $\begin{array}{c}\text { Divergente } \\
\text { Convergente }\end{array}$ \\
\hline $\begin{array}{l}\text { LPA } \\
\text { LPA*LPA }^{*}\end{array}$ & $\begin{array}{c}0.366187 \\
-0.097968\end{array}$ & $\Delta \%>0$ & $\begin{array}{c}\text { Convergente } \\
\text { Divergente }\end{array}$ \\
\hline $\begin{array}{l}\mathrm{RA} \\
\mathrm{RA}^{*} \mathrm{RA}\end{array}$ & $\begin{array}{r}0.677613 \\
-0.036195 \\
\end{array}$ & $\Delta \%>0$ & $\begin{array}{c}\text { Convergente } \\
\text { Divergente }\end{array}$ \\
\hline $\begin{array}{l}\mathrm{RP} \\
\mathrm{RP}^{*} \mathrm{RP}\end{array}$ & $\begin{array}{l}-0.219861 \\
-0.000396\end{array}$ & $\Delta \%>0$ & $\begin{array}{l}\text { Divergente } \\
\text { Divergente }\end{array}$ \\
\hline $\begin{array}{l}\mathrm{DF} \\
\mathrm{DF}^{*} \mathrm{DF}\end{array}$ & $\begin{array}{c}-0.274209 \\
0.004824 \\
\end{array}$ & $\Delta \%<0$ & $\begin{array}{c}\text { Convergente } \\
\text { Divergente }\end{array}$ \\
\hline $\begin{array}{l}\mathrm{EL} \\
\mathrm{EL}{ }^{*} \mathrm{EL}\end{array}$ & $\begin{array}{c}0.038437 \\
-0.000233\end{array}$ & $\Delta \%<0$ & $\begin{array}{c}\text { Divergente } \\
\text { Convergente }\end{array}$ \\
\hline $\begin{array}{l}\mathrm{LS} \\
\mathrm{LS}^{*} \mathrm{LS}\end{array}$ & $\begin{array}{c}0.359339 \\
-0.359178\end{array}$ & $\mathrm{dY} / \mathrm{dLS}>0$ & $\begin{array}{c}\text { Convergente } \\
\text { Divergente }\end{array}$ \\
\hline
\end{tabular}

Pela natureza dos indicadores, cada um tem seu resultado particular, na Tabela 3 as estimações foram conjuntas, para analisar seus coeficientes e o impacto de cada variável independente sobre o Produto, e, principalmente, se o resultado corrobora o sinal esperado individualmente. Os resultados mostram que existem convergências e divergências quanto ao coeficiente e o resultado esperado.

A análise linear parte da estimação do indicador de gestão individual em relação ao Produto (Y), que, pela teoria convencional, deve refletir um sinal esperado. Porém essa análise pode criar distorções nos resultados e, para isso, foram estimadas as equações não lineares de cada indicador de gestão para uma análise mais apropriada e sem distorções. 
Projetando a análise econométrica dos dados na direta relação entre os indicadores e o Produto, resultam especificamente para cada índice:

A LG em relação ao produto demonstrou linearmente que a decisão de ter seus direitos e obrigações a longo prazo é negativa, o que não corrobora seu sinal esperado (>0), porém essa é uma avaliação básica e superficial do resultado, pois, ao estimar a equação não linear do LG em relação ao Produto (Y), este se mostrou positivo, demostrando que existe um ponto de mínimo ótimo. Sua função é côncava, resultando que, no longo prazo, a decisão de liquidez pode se modificar e se tornar positiva a partir das decisões gerenciais da firma.

No caso do indicador de EG, as análises exaustivamente realizadas na literatura mostram que, em relação ao Produto, o EG deve ser negativo. Porém, nas empresas estudadas, o resultado da estimação foi positivo, divergindo do sinal esperado que mostre que, quanto menor o endividamento, melhor (<0). Essa conclusão é polêmica e contestável na prática, pois a firma pode estar endividada por motivos de decisão de investimento. O que colabora com a análise é a estimação não linear, mostrando que, nesse caso, o sinal esperado fica positivo. A função é convexa e tem ponto de máximo ótimo, convergindo com o sinal esperado na análise do EG pelo produto.

O LPA é um indicador ou output que depende de decisões internas e externas à firma, pois, no último caso, esse índice tem influência do mercado financeiro. Nos resultados, a estimação mostrou que sua relação com o Produto é positiva e converge com o resultado esperado (>0). Na análise não linear, a variável muda de positivo para negativo, mostrando que sua função é côncava e tem ponto de máximo.

Analisando a RA e a RP em relação ao Produto da Firma (Y), existem convergências e divergências quanto ao sinal esperado de cada índice. No caso da RA, a estimação mostrou que essa variável converge com o sinal esperado, mostrando-se positiva em relação ao 
Produto, o que demonstra que existe eficiência na gestão dos recursos da firma. Na análise não linear da RA, a função se mostra com ponto de máximo, e o coeficiente fica negativo. A RP carrega um resultado negativo, divergente do sinal esperado (>0), mostrando que a performance do lucro em relação ao capital próprio está negativamente relacionada com o Produto, linear ou não linearmente.

As decisões sobre EL e DF afetam diretamente os resultados da firma, principalmente no seu Produto. Nas estimações realizadas, os resultados entre DF e EL foram divergentes, seja na equação linear, seja na não linear. No primeiro caso, o coeficiente de DF foi negativo, convergindo com o sinal esperado (<0), e o EL foi positivo, divergindo do sinal esperado $(<0)$. Acentuando a análise para uma equação não linear, os resultados mudam, mostrando que a função da dependência financeira em relação ao produto fica positiva, e o endividamento líquido fica negativo.

\section{CONSIDERAÇÕES FINAIS}

A performance das empresas do setor de agronegócio listadas no segmento Novo Mercado da Bovespa foi o campo empírico do presente estudo, que objetivou medir o impacto da gestão, ou dos principais indicadores de gestão utilizados na literatura de finanças corporativas, por meio de modelagem econométrica, utilizando dados em painel. Os índices de lucratividade, liquidez, endividamento e rentabilidade, em um total de nove indicadores, formaram um constructo apropriado de análise para chegar ao objetivo.

Da estimação a partir de uma função de produção padrão e dos indicadores de desempenho como proxy para medir a governança no produto das firmas, foram realizados os testes de efeito fixo e efeito aleatório, por meio do teste de especificação de Hausman, que mostrou que todas variáveis são aleatórias. Com dados trimestrais 
de 2007:1 a 2011:4, das dez empresas listadas no NM da Bovespa, foi possível investigar os resultados apresentados dentro da área de finanças corporativas das empresas do agronegócio.

Corroborando os resultados encontrados em Modigliani e Miller (1958; 1963), Smith Jr. (1984) e Tirole (2006), a análise das escolhas financeiras das empresas e sua governança é fator fundamental para sua sobrevivência. Conforme os estudos mostrados em finanças corporativas de Modigliani e Miller (1958), afirmando que os resultados das firmas eram afetados pela escolha da estrutura financeira e, principalmente, pela maneira como as organizações eram geridas, este estudo revela a importância das decisões de investimento e endividamento nos indicadores de gestão.

Este trabalho permitiu compreender a dinâmica de cada indicador, observando a influência (individual e coletiva) dos índices e seus coeficientes, sendo que, a partir dos resultados, é possivel aumentar a discussão atual em finanças corporativas, tirando a padronização linear dos indicadores e dinamizando a análise de maneira não linear. Sob essa ótica não linear, é possível obter novos números da governança sobre os resultados das firmas, em mercados cada vez mais competitivos. E, em uma estrutura industrial em decadência, as escolhas estruturais serão as respostas mais analisadas pelos acionistas.

Finalmente, conclui-se que a influência dos indicadores no produto da empresa continua predominante quanto às variáveis Capital (k) e Trabalho (I), proporcionando o maior impacto no resultado, ou seja, no crescimento da firma. No caso especial de finanças corporativas, as estimações mostraram que variáveis intimamente interligadas ao mercado, como, por exemplo, o lucro por ação, são quase insignificantes no impacto inicial ao produto. Porém, ao analisar a dinâmica de cada variável, percebemos que todas têm seu ponto ótimo e são significantes estatisticamente na construção do produto. 
Performance das firmas do agronegócio listadas no novo mercado da Bovespa: um estudo econométrico

\section{REFERÊNCIAS}

ARROW, K.; DEBREU, G. Existence of equilibrium for a competitive economy. Econometrica, v. 22, n. 3, p. 265-290, jul. 1954.

ASSAF NETO, A. Estrutura e análise de balanços: um enfoque econômico e financeiro. 8. ed. São Paulo: Atlas, 2006. 191p.

BHAGAT, S.; BOLTON, B. Corporate governance and firm performance. Journal of Corporate Finance, v. 14, n. 3, p. 257-273, jun. 2008.

BRASIL. Ministério da Agricultura, Pecuária e Abastecimento (Mapa). Projeções do agronegócio: Brasil - 2009/2010 a 2019/2020. Brasília: Mapa, 2010.

CHANDLER, A. D. Organizational capabilities and the industrial enterprise. Journal of Economic Literature, v. 6, n. 3, p. 79-100, 1992.

. Scale and scope. Cambridge, MA: The Belknap Press of Harvard University Press, 1990. 760 p.

. The visible hand. Cambridge, MA: The Belknap Press of Harvard University Press, 1977. 608 p.

. Strategy and structure: chapters in the history of the American industry. Cambridge, MA: Harvard University Press, 1962.

MARRIS, R. L. The economic theory of managerial capitalism. London: Macmillan, 1971.

MODIGLIANI, F.; MILLER. M. H. The Costs of Capital, Corporate Finance, and the Theory of Investment. American Economic Review, v. 48, n. 3, p. 261-297, jun. 1958.

. Corporate Income Taxes and the Cost of Capital: A Correction. American Economic Review, v. 53, n. 3, p. 433-443, jun. 1963.

ORGANISATION FOR ECONOMIC COOPERATION AND DEVELOPMENT (OCDE). Annual Report, 2008.

PENROSE, E. The theory of the growth of the firm. White Plains, NY: M.E. Sharpe, 1959.

PEREZ JUNIOR, J. H.; BEGALLI, G. A. Elaboração e análise das demonstrações contábeis. 4 ed. São Paulo: Atlas, 2009. 
Michel CONSTANTINO; Dany Rafael Fonseca MENDES;

Reginaldo Brito da COSTA; Alexander Bruno PEGORARE

SMITH JR., C. W. The Theory of Corporate Finance: A Historical Overview. In: JENSEN, M. C.; SMITH, C. W. The Modern Theory of Corporate Finance. New York: McGraw-Hill, 1984.

STEINDL, J. Maturity and stagnation in american capitalism. New York: Monthly review press, 1952.

TIROLE, J. The Theory of Corporate Finance. Princeton, NJ, EUA: Princeton University Press, 2006. 